EM

\title{
MOBILIDADE TRANSFRONTEIRIÇA ENTRE PATO BRAGADO E NUEVA ESPERANZA NA FRONTEIRA BRASIL-PARAGUAY (1982) ${ }^{1}$
}

\author{
CROSS-BORDER MOBILITY BETWEEN PATO BRAGADO AND NUEVA \\ ESPERANZA ON THE BRAZIL-PARAGUAY FRONTIER (1982)
}

\section{MOBILIDADE TRANSFRONTEIRIÇA ENTRE PATO BRAGADO E NUEVA ESPERANZA NA FRONTEIRA BRASIL-PARAGUAY (1982)}

\author{
Aline KAMMER ${ }^{2}$ \\ Maristela FERRARI ${ }^{3}$
}

\begin{abstract}
Resumo: Historicamente os municípios de Pato Bragado (Paraná) e Nueva Esperanza- (Dept. de Canindeyú) na zona de fronteira do Brasil com o Paraguai mantinham fracas interações transfronteiriças, pois o rio Paraná, limite internacional, dificultava a travessia de um país ao outro. Mas, a formação do reservatório da hidrelétrica de Itaipu binacional (1982) favoreceu a mobilidade entre os dois lados do limite internacional e por consequência o desenvolvimento de inúmeras interações transfronteiriças. Este trabalho analisa os fatores que contribuíram para a crescente mobilidade transfronteiriça no segmento da zona de fronteira brasileiro-paraguaia formada pelos municípios de Pato Bragado (Paraná- BR) e Nueva Esperanza- (Canindeyú - PY). Neste sentido, podese questionar: a mobilidade transfronteiriça entre os habitantes é cotidiana ou esporádica? Como os Estados nacionais regulam ali os fluxos transfronteiriços? Para atingir o objetivo proposto, o método de pesquisa aqui adotado foi o qualitativo. A metodologia consistiu em leituras teóricas sobre, zona de fronteira, redes e fluxos e pesquisa de campo com moradores de Pato Bragado e Nueva Esperanza.
\end{abstract}

Palavras-Chave: Zona de fronteira brasileiro-paraguaia; Mobilidade Transfronteiriças; Pato Bragado/Nueva Esperanza.

\begin{abstract}
Historically, the municipalities of Pato Bragado (Paraná) and Nueva Esperanza- (Dept. de Canindeyú) in the border area between Brazil and Paraguay have maintained weak cross-border interactions, as the Paraná River, the international limit, made it difficult to cross from one country to another. However, the formation of the binational Itaipu hydroelectric reservoir (1982) favored mobility between the two sides of the international limit and, consequently, the development of numerous cross-border interactions. This paper analyzes the factors that contributed to the growing cross-border mobility in the segment of the Brazilian-Paraguayan border zone formed by the municipalities of Pato Bragado (Paraná-BR) and Nueva Esperanza- (Canindeyú - PY). In this sense, one can ask: is cross-border mobility between inhabitants daily or sporadic? How do national states regulate cross-border flows there? To achieve the proposed objective, the research method adopted here was qualitative. The methodology consisted of theoretical readings about, border zone, networks and flows and field research with residents of Pato Bragado and Nueva Esperanza.
\end{abstract}

Keywords: Brazilian-Paraguayan Border Zone; Cross-border Mobility; Pato Bragado/Nueva Esperanza.

\footnotetext{
${ }^{1}$ Esse trabalho integra pesquisa de mestrado custeada pela CAPES (Coordenação de Aperfeiçoamento de Pessoal de Nível Superior) no PPGG da UNIOESTE campus Marechal Cândido Rondon (PR), sob Orientação da Prof. $^{\text {a }}$ Dr $^{\mathrm{a}}$ Maristela Ferrari. O mesmo está vinculado ao Grupo de Estudos sobre Fronteira, Território e Ambiente (GEFTA).Agradeço a CAPES pelos recursos por meio da bolsa de mestrado destinados a pesquisa..

${ }^{2}$ Mestre pelo PPG em Geografia da Universidade Estadual do Oeste do Paraná/Campus Marechal Cândido Rondon. Agradeço a CAPES pela concessão de Bolsa para realização da pesquisa de mestrado. E-mail: alinealinekammer@outlook.com

${ }^{3}$ Doutora em Geografia. Professora do Programa de Pós-Graduação em Geografia da UNIOESTE - campus Marechal Cândido Rondon E-mail: maristela7ferrari@gmail.com
} 
Resumen: Históricamente los municipios de Pato Bragado (Paraná) y Nueva Esperanza- (Dept. de Canindeyú) en la zona fronteriza entre Brasil y Paraguay han mantenido interacciones transfronterizas débiles, ya que el río Paraná, límite internacional, dificultaba el paso de un país a otro. Sin embargo, la formación del embalse hidroeléctrico binacional de Itaipú (1982) favoreció la movilidad entre los dos lados del límite internacional $\mathrm{y}$, en consecuencia, el desarrollo de numerosas interacciones transfronterizas. Este trabajo analiza los factores que contribuyeron a la creciente movilidad transfronteriza en el segmento de la zona fronteriza brasileño-paraguaya formado por los municipios de Pato Bragado (Paraná-BR) y Nueva Esperanza- (Canindeyú - PY). En este sentido, cabe preguntarse: ¿la movilidad transfronteriza entre habitantes es diaria o esporádica? ¿Cómo regulan los estados nacionales los flujos transfronterizos allí? Para lograr el objetivo propuesto, el método de investigación adoptado aquí fue cualitativo. La metodología consistió en lecturas teóricas sobre, zona de frontera, redes y flujos e investigación de campo con pobladores de Pato Bragado y Nueva Esperanza.

Palabras Claves: Zona fronteriza brasileño-paraguaya; Movilidad transfronteriza; Pato Bragado/Nueva Esperanza.

\section{Introdução}

Os municípios de Pato Bragado (Paraná-BR) e Nueva Esperanza (Canindeyú-PY) estão localizados num segmento da zona de fronteira brasileiro-paraguaia, (Figura 1). O limite internacional é antigo, data de 1872, traçado sob o Rio Paraná. Desde sua demarcação, o limite foi considerado obstáculo para a travessia entre os dois páises, pois o rio Paraná era encachoeirado e apresentava desníveis dificultando a navegação. Mas, tal característica foi alterada, notadamente após formação do reservatório de água da Usina Hidrelétrica da Itaipu Binacional (1982) o que favoreceu a navegação e como efeito contribuiu para o crescimento da mobilidade transfronteiriça, através do estabelecimento de redes de interações transfronteiriças. Neste sentido, pode-se questionar: Que fatores levam os habitantes atravessar o limite internacional gerando mobilidade transfronteiriça? A mobilidade é cotidiana ou esporádica? Como os Estados nacionais regulam ali os fluxos transfronteiriços? Essas questões estabelecem um guia para o desenvolvimento do presente trabalho.

Para atingir o objetivo proposto, o método de pesquisa adotado foi o qualitativo. Não obstante, os procedimentos metodológicos utilizados para o trabalho desenvolveram-se em três etapas; inicialmente com leituras teóricas sobre, zona de fronteira, mobilidade transfronteirça, redes e fluxos e posteriormente, com pesquisa de campo com moradores de Pato Bragado e Nueva Esperanza. O texto foi estruturado em duas partes: a primeira desenvolve uma reflexão sobre os conceitos de zona de fronteira, redes e fluxos e mostra como tais conceitos podem auxiliar na análise de uma problemática sobre mobilidade transfronteiriça; já na segunda parte do trabalho, anlisa-se os principais fatores que têm 
EM

QUESTÃO

V.13 N. $04 \bullet 2020$

pág. 81-95

contribuído ao aumento da mobilidade transfronteiriça. Finalizamos o trabalho indicando que as assimetrias sócio-espaciais são o motor da mobilidade transfronteirça entre Pato Bragado e Nueva Esperanza.

Figura 1 - Localização dos municípios de Pato Bragado e Nueva Esperanza.
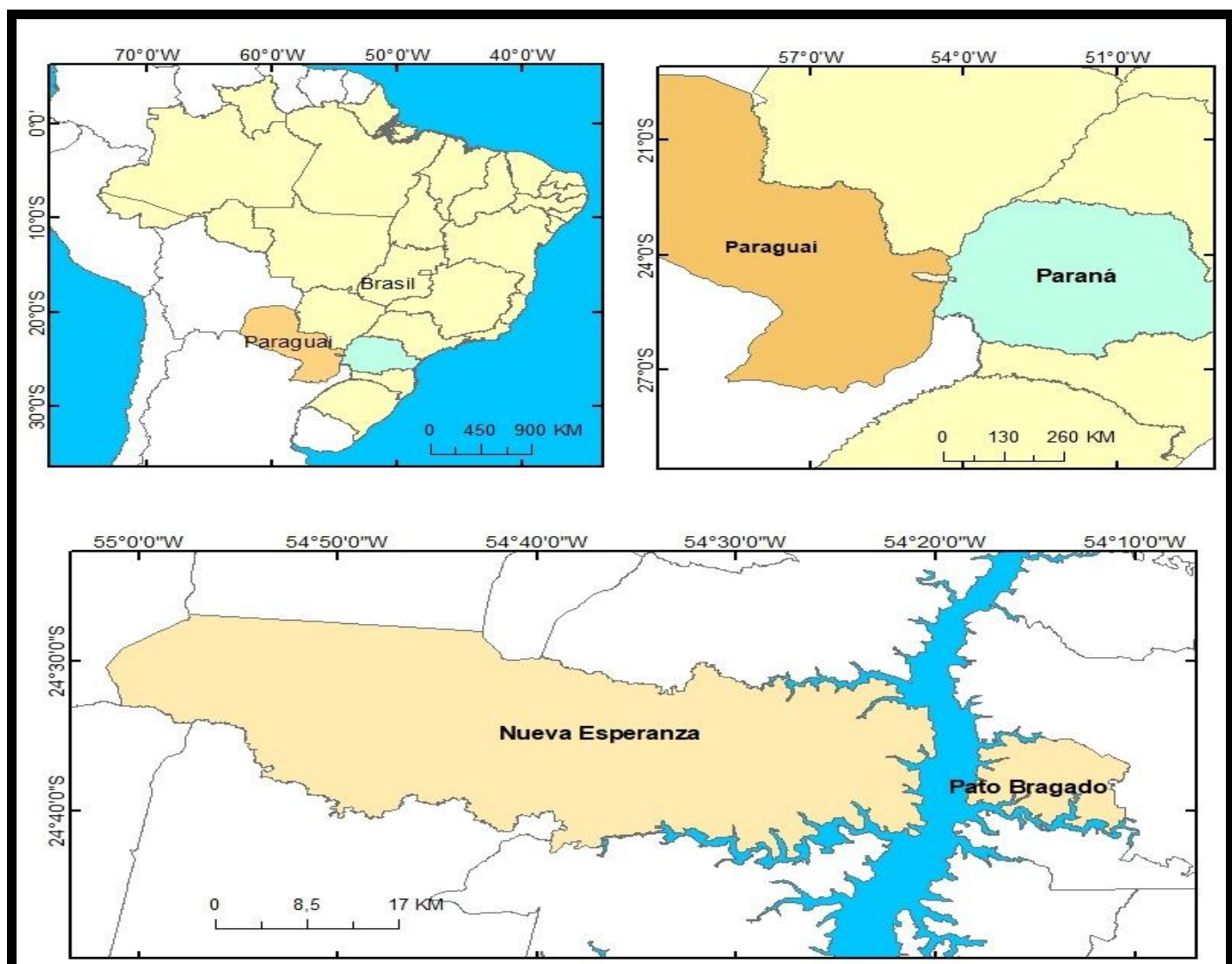

\section{Legenda}

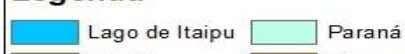

Brasil Paraguai

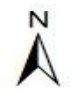

Base cartográfica: ITCG, IBGE, DGEEC

Fonte: Kammer, 2020.

\section{Zona de fronteira e mobilidade transfronteirça}

Refletir sobre mobilidade transfronteiriça é antes de tudo indicar o que se compreende por zona de fronteira. De acordo com Ferrari, (2013, p. 88), "a zona de fronteira é formada pelos espaços que se encontram na confluência do limite entre dois territórios nacionais". Segundo essa autora, “[...], a zona de fronteira remete à ideia de ligação entre territórios e, 
para apreendê-la é necessário considerar o conjunto territorial de ambos os lados do limite internacional, pois se trata de outra territorialidade que vai reconfigurar o espaço territorial dividido".

Analisando os espaços fronteiriços da América do Sul, Machado (2005) propõe pensar a zona de fronteira como "sistema aberto" e sugere que em análises que abordem fluxos transfronteiriços o conceito mais apropriado é o de zona de fronteira. Para essa autora, "a zona de fronteira se caracteriza por interações transfronteiriças que formam um meio geográfico próprio só perceptível na escala local/regional", (MACHADO, 2005, p. 259). Ao ponderar sobre interações transfronteiriças Ferrari (2013) argumenta que:

Em zonas de fronteira as interações [...] não se desenvolvem somente no sentido econômico, elas envolvem todo um conjunto de interações materiais e imateriais, como as simbólicas, culturais e identitárias, pois são vinculadas umas às outras justamente porque elas são estabelecidas por sujeitos (fronteiriços) que em sua realidade cotidiana atuam de forma relacional num conjunto sócio-territorial que envolve os dois lados do limite internacional (FERRARI, 2013, p. 88-89).

Consideranto as reflexões acima se pode dizer que as populações limítrofes praticam diferentes tipos de mobilidade. Os habitantes de espaços fronteiriços frequentemente fazem compras de produtos e ou mercadoiras num ou noutro lado do limite internacional, as compras, normalmente, são induzidas pelos diferencias de preços e/ou ausência de produtos e mercadorias, de modo geral, num dos lados do limite e presentes no outro. Sem dúvida que as interações econômico-comerciais são mais evidentes e aparentemente geram mais mobilidade transfronteirça, mas a migração, a liberdade de escolha do lugar de residência, o lugar de trabalho, a liberdade de escolha do lugar de lazer também gera mobilidade transfronteirça em diferentes graus.

Não obstante, comumente as assimetrias sócio-territoriais entre um e outro lado do limite internacional induzem as populações a atravessar o limite cotidianamente em busca de serviços especializados, como os serviços de educação e serviços de saúde. Portanto, são práticas espontâneas que geram mobilidade e que ocorrem em diferentes níveis e por diversas razões. A migração e a proximidade geográfica constituem redes de amizade e parentesco e estimula a mobilidade gerando constantes fluxos de circulação num ou noutro lado do limite internacional.

Neste sentido, reletir sobre fatores da mobilidade transfronteirça é também considerar o conceito de rede. De acordo com Ferrari (2015, p. 248) o conceito de rede auxilia em pesquisas sobre mobilidade transfronteiriça tanto como instrumento analítico quanto 
EM

QUESTÃO

V.13 N. $04 \bullet 2020$

pág. 81-95

metodológico. Dias (2002) indica que uma das propriedades importantes da rede é a conectividade por representar ligações entre pessoas e lugares interligando vias por onde circulam bens materiais e informações. É neste sentido que o conceito de conceito de rede esta sendo aqui mobilizado para avaliar fluxos reticulares e/ou deslocamentos sócio-espaciais transfronteiriços.

Ao refletir sobre redes geográficas, Santos (1999) argumenta que a rede é formada por um conjunto de pontos fixos, esses fixos são interligados por fluxos por onde circulam bens materiais e imateriais. Tal ponderação pode ser associada às práticas sócio-espaciais transfronteiriças já que, normalmente, elas ligam dois conjuntos sócio-territoriais, como, por exemplo, Nueva Esperanza (Paraguay) e Pato Bragado (Brasil), ligação que se faz pelo estabelecimento de redes sociais transfronteirças por onde circulam bens materiais e imateriais.

Corrêa (1997) também auxilia ao afirmar que o conceito de rede pode ser definido como um conjunto de localizações geográficas interconectadas entre si, por certo número de ligações. As redes geográficas são, segundo o autor, redes sociais espacializadas, são sociais em virtude de se estabelecer por interesses dos homens e de suas relações (CORRÊA, 2012). Para Santos (1999, p 209) a rede é antes de tudo social pelas pessoas, mensagens e valores que a freqüentam.

Considerando as ponderações de Santos (1999) e Corrêa (2012) pode-se afirmar que as redes transfronteirças são estabelecidas por pessoas (habitantes da fronteira) com interesses diversos. Neste sentido, rede serve tanto como um conceito teórico quanto instrumento metodológico para a análise da mobilidade transfronteiriça em zona de fronteira. Por exemplo, desde o final dos anos 1970 e, sobretudo, década de 1980, inúmeros brasileiros da região oeste do Paraná migraram para o lado paraguaio, em parte, devido ao esgotamento de terras agrícolas e, em parte, pelos processos de desterritorialização decorrente da construção de obras técnicas, como, por exemplo, a hidrelétrica Itaipu binacional entre Brasil e Paraguay e a formação do reservatório de águas da Itaipu.

Assim, os migrantes brasileiros no interior do Paraguai, vão pôr em curso várias redes sociais transfronteiriças, em diversos pontos ao longo do limite brasileiro-paraguaio. Entre Pato Bragado e Nueva Esperanza o estabelecimento de redes sociais transfronteirças se dá após 1982, especialmente após a formação do reservatório de águas da Itaipu binacional, já que tal obra sobre o rio Paraná transformou o rio encachoeirado e de difícil navegabilidade num lago que favoreceu a navegação e por consequência a mobilidade transfronteiriça. 
EM

Embora no passado tenha havido relações econômico-comerciais entre Brasil e Paraguay via Pato Bragado e Nueva Esperanza (exportação e importação de recursos naturais, hortelã, café, madeira, erva-mate, etc.), aquele ponto de fronteira nunca foi alfandegado e a revelia dos Estados nacionais os habitantes fronteiriços, por diferentes razões, interagem cotidianamente. Mesmo no contexto do MERCOSUL as interações transfronteirças tanto materiais quanto imateriais são consideradas ilegais, pelos organismos de segurança dos Estados nacionais, pois aquela passagem entre Brasil e Paraguay não foi habilitada ao comércio e turismo internacional.

\section{Fatores que induzem a mobilidade transfronteirça entre populações de Pato Bragado (Paraná- Brasil) e Nueva Esperanza (Canindeyu-Paraguai)}

Ainda que no passado tenha havido relações econômico-comerciais entre Brasil e Paraguay via Pato Bragado e Nueva Esperanza, onde inclusive foi estruturado o Porto Britânia e o Puerto Marangatú (Figura 2, 3, 4 e 5) tais relações não estabeleceram mobilidade transfronteiriça cotidiana, pois as atividades econômico-comerciais do passado dependiam de ciclos econômicos, como, por exemplo, a colheita do chá (hortelã), do café, da erva-mate, dentre outros e isso não gerava interações cotidianas. Segundo a pesquisa de campo, a interações transfronteiriças cotidianas entre Pato Bragado e Nueva Esperanza passaram a ser mais freqüentes a partir de meados de 1985, notadamente, com a presença de migrantes brasileiros no lado paraguaio. A formação do reservatório de águas da Itaipu binacional (1982) também criou facilidades para a passagem de um país ao outro, mas o fator que mais contribuiu e ainda contribui para a crescente mobilidade transfronteiriça entre Pato Bragado e Nueva Esperanza são as profundas assimetrias socioterritoriais entre os dois lados do limite internacional.

O lado paraguaio é formado pela Colônia Marangatú que dista em aproximadamente $70 \mathrm{~km}$ da cidade de Nueva Esperanza. As vias terrestres são extremamente precárias e não pavimentadas. É uma área essencialmente agrícola e, desde 2019, já reivindica sua emancipação política, reivindicação encabeçada, notadamente, por brasileiros radicados no lado Paraguaio. A localidade tem um único posto de saúde para atendimento de primeiros socorros e o comércio de venda de produtos e mercadorias de primeiras necessidades é escasso e não atende as necessidades de seus habitantes. 
EM

QUESTÃO

V.13 N. $04 \bullet 2020$

pág. 81-95

Figura 2 - Porto Britânia na década de 1950.

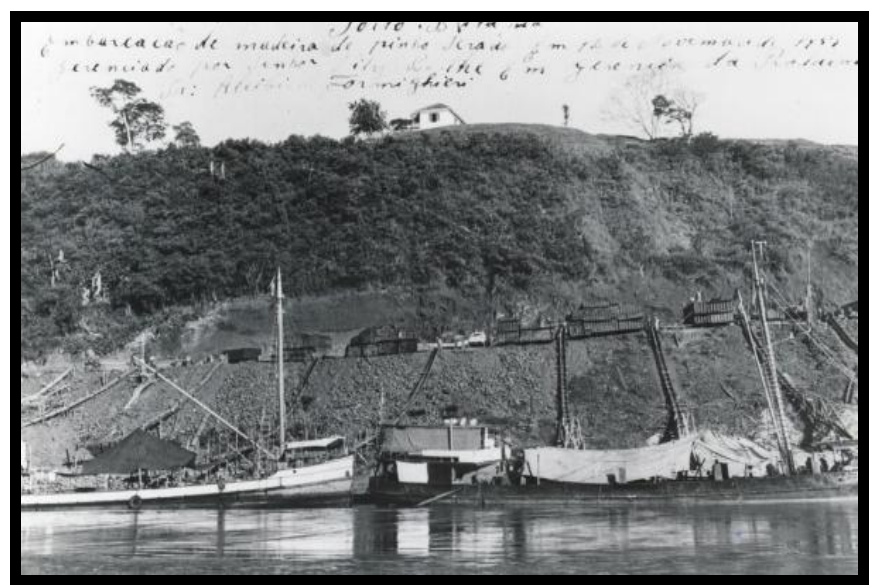

Fonte: Museu de Pato Bragado, 2019.

Figura 3 - Porto Britânia, em 2019.

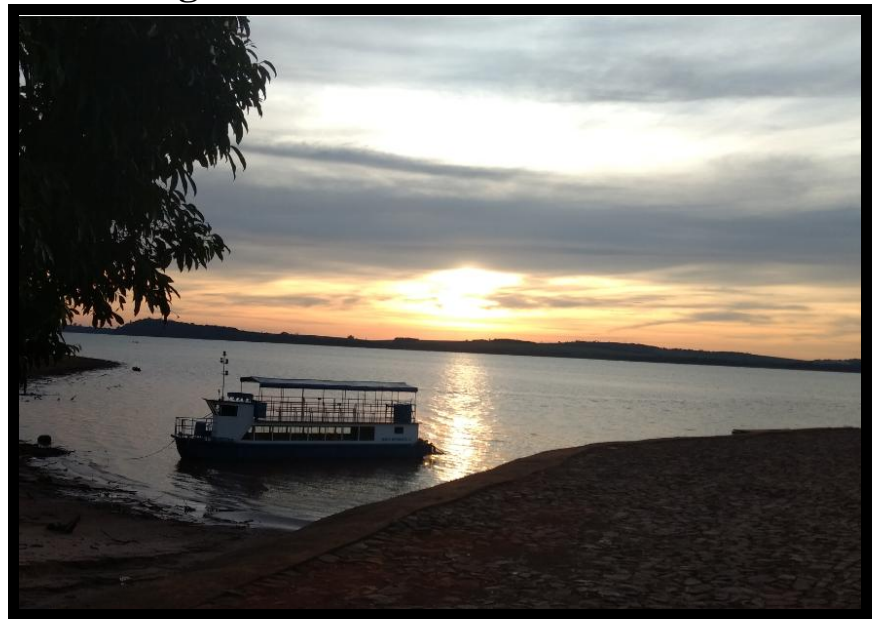

Fonte: foto da autora a partir do trabalho de campo, 2019.

Figura 4 - Vista de Puerto Marangatú para o Porto Britânia, 1950.

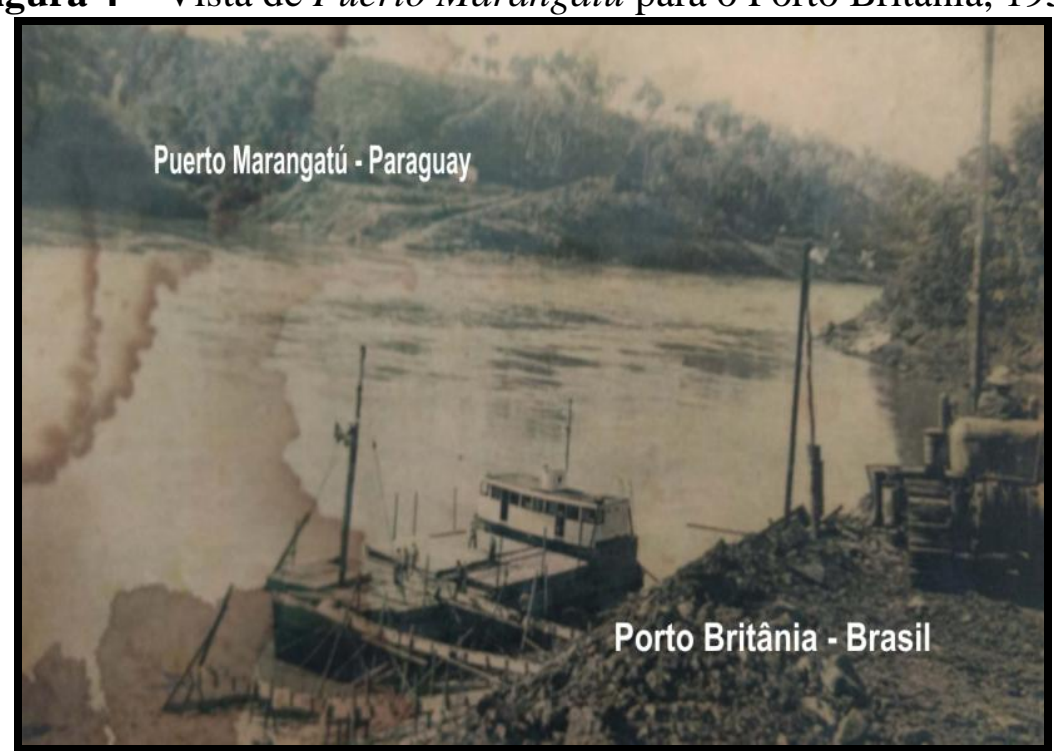

Fonte: Museu de Pato Bragado, organização e arte a autora. 
Figura 5 - Localização de Puerto Marangatú e Porto Britânia.

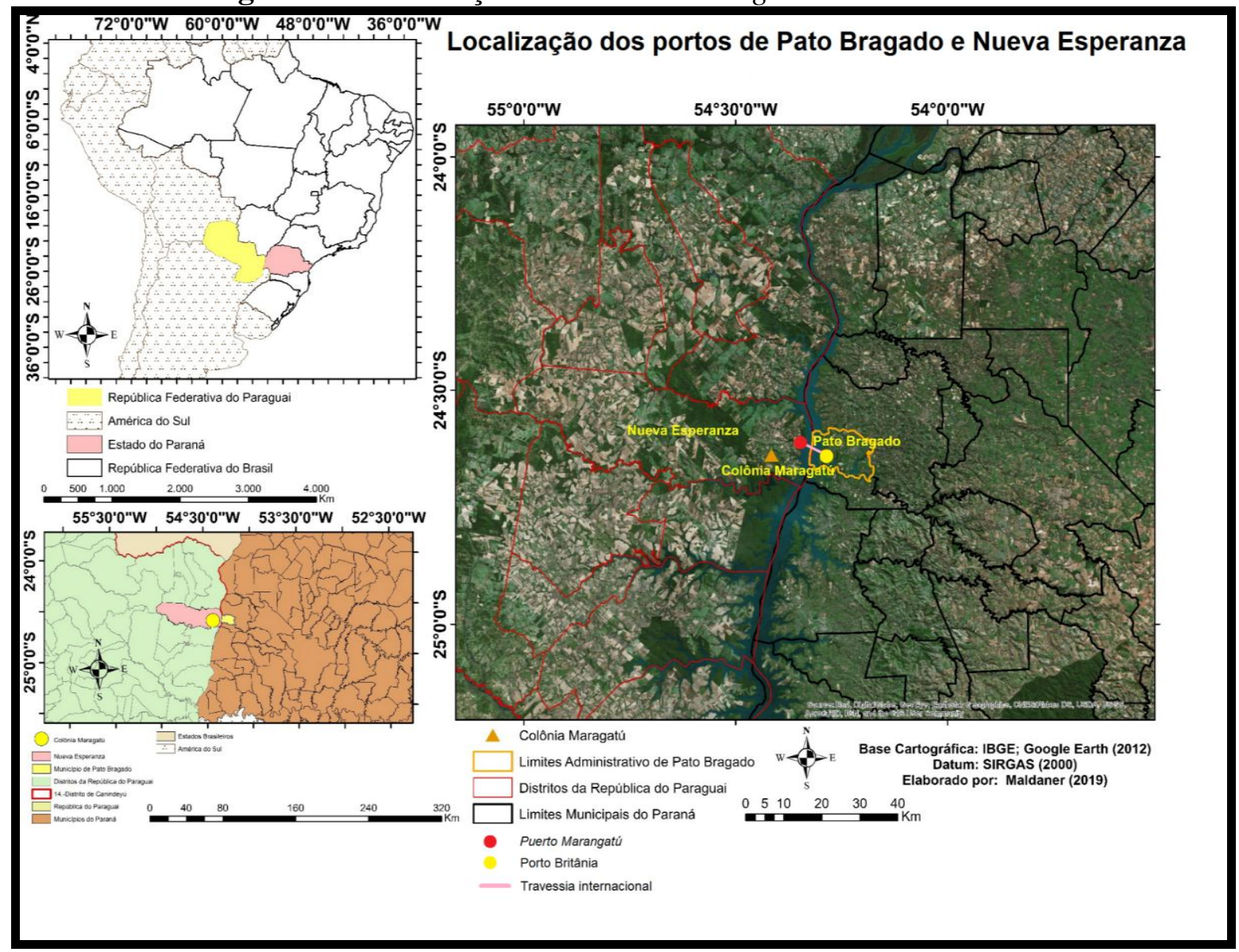

Fonte: Kammer, 2020.

A carência de serviços básicos como os de saúde, educação e comércio revela profundas assimetrias socioterritorias frente ao lado brasileiro. Pela distância geográfica da cidade de Nueva Esperanza e ausência de serviços básicos no lado paraguaio, a população de Colônia Marangatu passou a estabelecer freqüentes interações transfronteiriças com Pato Bragado.

As interações transfronteiriças foram sendo promovidas, especialmente, por brasileiros residentes no o lado paraguaio e também por agricultores residentes em Pato Bragado, mas que possuem terras no lado paraguaio. A forte presença de brasileiros no lado paraguaio, desde 1980, foi fomentando redes socias transfronteiriças cotidiana entre os dois lados do limite internacional. Do lado paraguaio em direção ao lado brasileiro se estabeleceram redes em busca de serviços do sistema de saúde, do sistema de educação e comércio de modo geral.

Segundo a pesquisa de campo, entre Colônia Marangatú e Pato Bragado há uma rede de trabalhadores transfronteiriços (homens e mulheres) que residem num país e trabalham no outro, ou seja, atravessam cotidianamente o limite internacional para trabalhar num ou noutro 
lado do limite internacional. Por exemplo, proprietários de terras agricultáveis em lado paraguaio, mas que residem no lado brasileiro, comumente, no período de plantio e colheita, contratam mão de obra brasileira para trabalhos agrícolas no lado paraguaio. Por outro lado, habitantes residentes em lado paraguaio, sobretudo filhos de migrantes brasileiros, buscam e trabalham em diversas atividades em Pato Bragado, inclusive no setor terciário. Esses trabalhadores fomentam a mobilidade transfronteiriça.

As redes no sistema de saúde são estabelecidas principalmente por brasileiros radicados no Paraguai. São redes que se estabelecem não apenas de Colônia Marangatú, mas de todo departamento de Nueva Esperanza, já que o sistema público de saúde naquele departamento é precário. Além desse fator, migrantes brasileiros e seus filhos residentes em lado paraguaio buscam serviços de saúde em Pato Bragado ou outras cidades brasileiras, em parte, pela ausência de serviços médico-hospitalares especializados e, em parte, por confiarem mais nos serviços ofertados em lado brasileiro. Não obstante, pelos laços de amizade e parentesco e pela manutenção da documentação brasileira, muitos brasileiros residentes em lado paraguaio conseguem tratamento de saúde pelo Sistema Único de Saúde (SUS). O acesso ao atendimento de saúde nas clínicas públicas de Pato Bragado é possível mediante apresentação do cartão do SUS e/ou ter o cadastro de munícipe.

No sentido de adquirir os documentos necessários para a comprovação de endereço, os moradores de Nueva Esperanza, notadamente migrantes brasileiros e seus filhos, articularamse através de redes de amigos ou familiares e utilizam contas de luz, água e outros documentos comprobatórios autenticados em Cartório de Registro o que lhes garante, mesmo morando no Paraguai, certos tipos de serviços públicos em lado brasileiro. Além do mais, foi observado que moradores do departamento de Nueva Esperanza possuem propriedades em Pato Bragado (casas e terrenos) o que facilita apresentação de documentação para atendimento no SUS.

Pato Bragado é uma pequena cidade do oeste do Paraná e, também, não apresenta um sistema de saúde dotado de atendimento de média e alta complexidade, no entanto, quando um paciente necessita de tratamento mais especializado, é orientado para centros mais especializados, o mesmo ocorre quando pacientes do lado paraguaio são atendidos em Pato Bragado e necessitam de tratamento de saúde de média e alta complexidade. Portanto, a rede estabelecida do lado paraguaio para o lado brasileiro, em busca de serviços médicohospitalares, não se restringe a Pato Bragado, se estende a outros municípios da região oeste paranaense, dentre eles Entre Rios do Oeste, Marechal Cândido Rondon, Toledo e Cascavel (Figura 6). 
Figura 6 - Nueva Esperanza (Paraguai): emissão de fluxos em busca de serviços médicohospitalares na região fronteiriça do oeste do Paraná- Brasil.

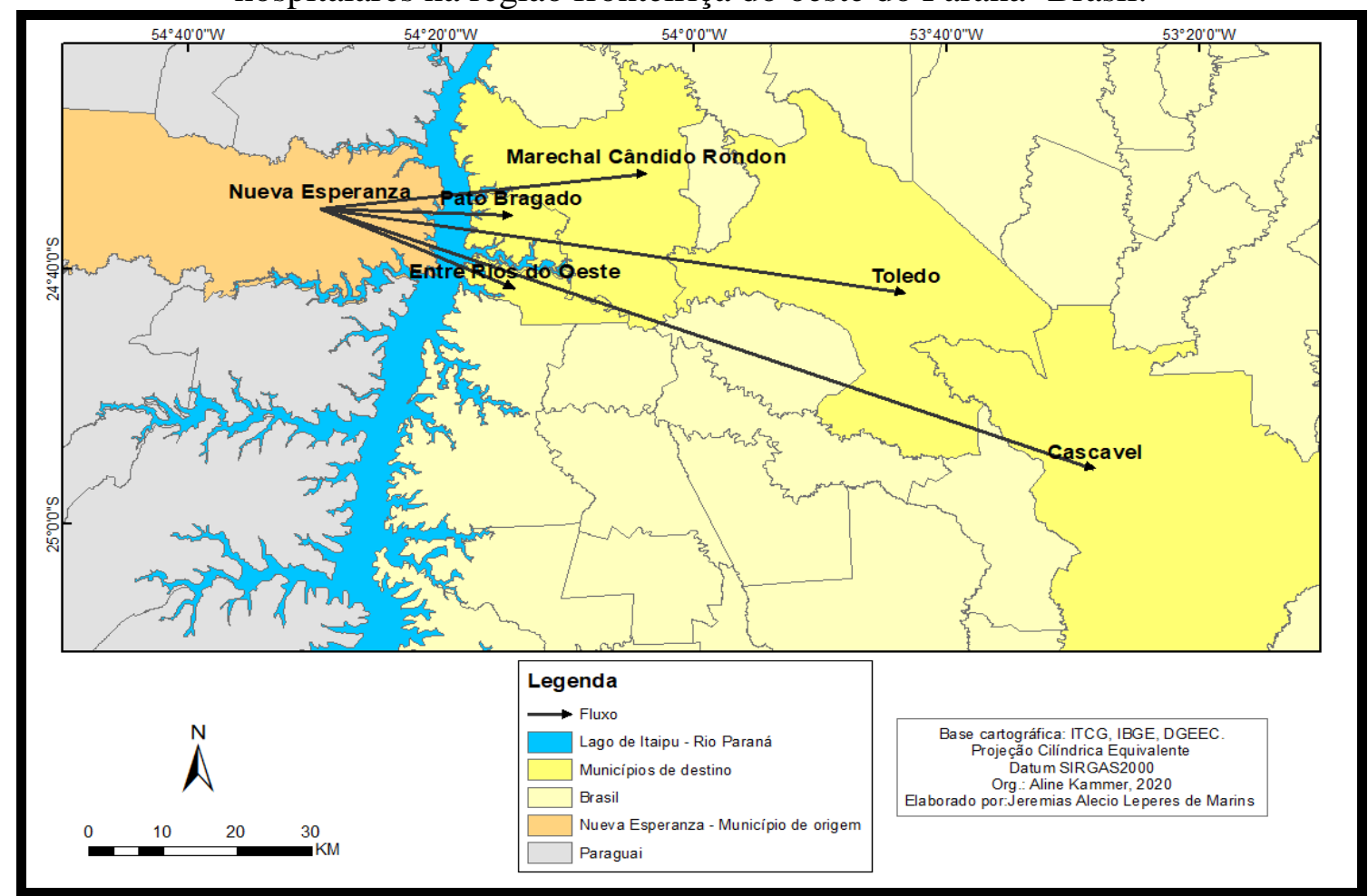

Fonte: Kammer, (2020)

Consultas médicas de rotina, exames, tratamento odontológico, compra de medicamentos, atendimento a gestantes e crianças e demais serviços têm contribuído para crescente mobilidade transfronteiriça e indicam um comportamento recente mas que anima a zona de fronteira brasileiro-paraguaia formada pelos municípios de Nueva Esperanza e Pato Bragado. Segundo a pesquisa de campo, não há jurisprudência quanto ao direito do estrangeiro fronteiriço ao SUS, bem como aporte de recurso estadual ou federal para que o município fronteiriço atenda essa demanda.

Obviamente que são realizados atendimentos de emergência e/ou urgência, como picadas de cobra, baleados, acidentados em máquinas agrícolas, acidentados no trânsito, escalpelados em barcos, entre outros. Mas, já existe preocupação dos gestores sobre à capacidade financeira para atender essa demanda, uma vez que o recurso recebido é pelo número de habitantes residentes no município, ficando, portanto, fora da contagem os estrangeiros, mesmo sendo brasileiros radicados ou residente do outro lado da fronteira (STRADA, 2018). Uma alternativa para "desafogar" os sistemas municipais de saúde seria uma política pública bilateral que injetasse verbas destinadas à saúde nessas áreas fronteiriças. Uma tentativa de resolver o problema se deu através do governo brasileiro com o Ministério 
da Saúde pelo programa chamado SIS-Fronteira, em 2005, mas, por inúmeras razões, esse projeto não avançou.

Além da rede em busca de serviços médico-hospitalares, do lado paraguaio para o lado brasileiro, desde a década de 1980, constata-se uma rede na busca de serviços do sistema educacional. Assim como na rede de serviços de saúde, os migrantes brasileiros tem preferência pelo sistema de educação brasileiro, considerado melhor do que aquele em lado paraguaio. Além disso, entrevistados apontam que há um problema recorrente no lado paraguaio, qual seja, o cancelamento das aulas em períodos chuvosos, devido às pessimas condições da rede viária e da rede de energia elétrica. Assim, nas escolas de Pato Bragado há constante presença de alunos residentes no lado paraguaio, especialmente de localidades como Colônia Marangatú, Vila Primero de Marzo, Colônia Velha, Km 18 e Colônia Itambey. Nas entrevistas os moradores das localidades acima mencionadas consideram o ensino paraguaio de "pouca qualidade". Embora alguns estudantes paraguaios optem por morar em casa de amigos e parentes de seus pais, muitoas crianças atravessam o limite dirariamente para estudar nas escolas de Pato Bragado. Nesse sentido, esses fluxos diarias geram o que aqui denominamos de mobilidade transfronteirça cotidiana.

Outros fluxos que geram mobilidade transfronteirça cotidiana são de natureza diversas, dentre eles, os fluxos estabelecidos por pessoas que visitam amigos e parentes num ou noutro lado da fronteira, os fluxos de lazer participação em bailes, jogos, festas religiosas e festas populares e os fluxos os econômico-comerciais pelos diferenciais de preços ou pela ausência de produtos e mercadorias, como os alimenticios, num dos lados da fronteira. Segundo a pesquisa de campo, os fluxos mais densos são aqueles de compras que se estabelecem de Nueva esperanza para Pato bragado. Grande parte da população da localidade Colônia Marangatú, e outras localidades de Nueva Esperanza, fazem suas compras mensasis ou semanais nos supermercados de Pato Bragado. Esses fluxos não são motivados apenas os diferencias de preços, mas principalmente pela falta deles em coméricos do lado paraguaio. A proximidade geográfica com Pato Bragado é outro fator que impulsiona os moradores do lado paraguaio a realizarem suas compras de gêneros alimentícios no lado brasileiro. Segundo a pesquisa de campo, os fluxos gerados pelas compras em supermercados e outros tipos de comercios, como lojas de roupas, são os mais densos e contribuem para a crescente mobilidade transfronteirça.

Entre Nueva Esperanza e Pato Bragado há também uma geografia dos fluxos noturnos emitidos, sobretudo, pelas redes ilegais. Esse ponto de fronteira entre Brasil e Paraguai tem sido muito ulitizado para atravessar produtos e mercadorias do Paraguai para o Brasil. Dentre 
os principais produtos que saem do Paraguai e entram ilegalmente no país destaca-se cigarro, eletrônicos e agrotóxicos destinados a região e a outras escalas regionais do país. Neste sentido, a mobilidade transfronteirça não ocorre somente durante o dia, mas igualmente durante a noite.

O meio de transporte de um lado ao outro da fronteira é realizado via balas ou barcos particulares. As estruturas dos pontos de embarque e desembarque de pessoas são extremamente precarias e por ora, não há nenhuma intensão do governo brasileiro ou do governo paraguaio em habilitar ou alfandegar aquele ponto de passagem entre os dois territorios. Portanto, todas as interações transfronteirças que lá ocorrem são, do ponto de vista dos Estados nacionais, ilegais, pois se dão fora dos pontos legalizados para o trânsito de pessoas e mercadorias entre os dois países. Mesmo no contexto da integração regional do Mercosul, segundo a Polícia Federal brasileira, todas as atividades que lá ocorrem, inclusive a passagem de pessoas de um território ao outro, são ilegais já que não é passagem oficializada entre os dois países e a qualquer momento os Estados nacionais podem impedir/fechar a passagem de um território ao outro. Neste sentido, seria adequado que dentro do Mercosul fossem criadas políticas para o trânsito de pessoas residentes em zonas de fronteira, inclusive em pontos de passagem não habilitados ao trânsito internacional, sobretudo face a necessidades básicas da população limítrofe. Atualmente, a cooperação transfronteirça em nível de Mercosul é praticamente inexistente, ela existe informalmente mais no nível local, ou seja, entre habitantes dos dois lados do limite internacional.

\section{Considerações finais}

O objetivo deste trabalho consistiu em analisar os fatores que contribuíram para a crescente mobilidade transfronteiriça no segmento da zona de fronteira brasileiro-paraguaia formada pelos municípios de Pato Bragado (Paraná- BR) e Nueva Esperanza- (Canindeyú PY). Assim, o trabalho revela que, embora a formação do Reservatório da Usina Hidrelétrica de Itaipu binacional (Brasil-Paraguai), em 1982, tenha facilitado o estabelecimento de fluxos e redes entre os dois lados do limite, as interações, em sua maioria, ocorrem fundamentalmente devido as assimetrias socioterritoriais (diferenças e desigualdades). Portanto, as assimetrias são promotoras da crescente mobilidade transfronteiriça e mostra os processos e formas que assumem tais diferenças sociais nas duas territorialidades limítorfes. 
Portanto, foi possível compreender que as assimetrias entre Nueva Esperanza e Pato Bragado estão na origem das interações transfronteiriças.

O trabalho mostra ainda que, a rede da migração brasileira para o lado paraguaio tem grande peso na emissão de fluxos reticulares transfronteiriços, são fluxos que rompem os limites territoriais e geram a mobilidade transfronteiriça. Ainda que não seja uma passagem legal para o trânsito internacional entre Brasil e Paraguai, os moradores da fronteira atravessam o limite internacional cotidianamente para fazer compras, para trabalhar, em busca de serviços médico-hospitalares, em busca de serviços do sistema educacional, para lazer e outras necessidades.

A pequena cidade de Pato Bragado é para as comunidades rurais do lado paraguaio o motor dos fluxos transfronteirços. Em outros termos, essa zona de fronteira é formada por realidades diferentes, de um lado uma cidade e de outro áreas essencialmente agrícolas e despossuídas de equipamentos de necessidades básicas o que induz os indivíduos a buscar cotidianamente o que necessitam na pequena cidade brasileira. Além disso, as comunidades rurais do lado paraguaio estão distantes da sede do departamento de Nueva Esperanza em aproximadamente 70 quilômetros, mas a proximidade de comunidades agrícolas como Marangatú, Km 13, Colônia Itambey, Troncal 4, Cerro Azul com a cidade de Pato Bragado é um fator determinante na tendência dos fluxos para o lado brasileiro. Em outros termos, devido à proximidade geográfica e a carência de serviços básicos, a população paraguaia atravessa cotidianamente o limite internacional em busca do que necessitam em Pato Bragado, mas quando aquela pequena cidade não oferece determinados tipos de serviços de que necessitam os paraguaios buscam atender suas necessidades em outros centros ou pólos, como, Toledo, Cascavel e/ou Marechal Cândido Rondon.

Pela mobilidade transfronteirça entre pato Bragado e Nueva Esperanza é possível constatar que a população uniu as duas margens do rio Paraná e isso, em parte, só foi possível com a formação do reservatório de águas ou lago da Itaipu binacional que criou condições para a travessia de um país ao outro. Isso explica, em parte, a crescente mobilidade transfronteirça, mas como dito anteriormente, a facilidade de navegação pelo lago da Itaipu binacional facilitou a travessia do limite, mas o fator determinante é sem dúvida as assimetrias socioterritoriais. Assim, embora os estados nacionais regulem os fluxos como ilegais, já que aquele ponto de passagem não é alfandegado, seria adequada uma política de MERCOSUL visando à liberdade de circulação de um território ao outro, notadamente face as necessidades básicas da população fronteiriça. 
Por outro lado, é em parte pelo distanciamento geográfico da sede políticoadministrativa do departamento de Nueva Esperanza que a população de Colônia Marangatú atualmente reivindica sua emancipação política. Obviamente que existem outros objetivos, notadamente políticos e econômicos, como os royalties da Itaipu binacional. É interessante notar que a ideia da emancipação política de Colônia Marangatú parte, fundamentalmente, de brasileiros radicados no Paraguai e que já divulgam que, com a emancipação de Colônia Marangatú, os royalties da Itaipu binacional seriam remetidos ao novo município paraguaio. Há também clara intenção de fundar uma cidade na área rural do lado paraguaio, uma questão que merece novas reflexões.

\section{Referências Bibliográficas}

CORRÊA, Roberto Lobato. Dimensões de análise das redes geográfica. In: Trajetórias geográficas. Rio de Janeiro: Bertrand Brasil, 1997.

Redes geográficas: reflexões sobre um tema persistente. Cidades, São Paulo, v. 16, p.199-2018, 2012. Semestral. Disponível em: http://revista.fct.unesp.br/index.php/revistacidades/article/view/2378/2122

Acesso em: 1 mar. 2019.

DIAS, Leila Christina. Redes: emergência e organização. In: CASTRO, I.; GOMES, P. C. da C. e CORRÊA R. L. (Org.). Geografia: conceitos e temas. Rio de Janeiro: Bertrand Brasil, 2002.

Os sentidos da rede: notas para discussão. In: DIAS, Leila Christina e SILVEIRA, Rogério L. Lima da. Redes, sociedades e territórios. Santa Cruz do Sul: Edunisc, 2005.

FERRARI, Maristela. Conflitos e povoamento na fronteira Brasil-Argentina: Dionísio Cerqueira (SC), Barracão (PR), Bernardo de irigoyen (Misones). Florianópolis: Editora da UFSC, 2010.

. Zona de fronteira, ciudades gêmeas e interações transfronteiriças no contexto do MERCOSUL. Buenos Aires (Argentina): Revista Transporte y Territorio /9. ISSN 18527175, 2013. p. 87-107. Disponível em: https://doi.org/10.34096/rtt.i9.305. Acesso em abril de 2019

- Redes da migração brasileira no nordeste da Província de Misiones - Argentina (Século XX). In: VALENTINI, D. J e MURARO, V.F. Colonização, conflitos e convivências nas fronteiras do Brasil, da Argentina e do Paraguai. Porto Alegre: Letra \& Vida; Chapecó: EdUFFS, 2015.

Territorialidades transfronteiriças na zona da fronteira seca internacional BrasilArgentina. In: DIAS, Leila C. e FERRARI, Maristela. (Org.). Territorialidades humanas e redes. $2^{\mathrm{a}}$ ed. Florianópolis: Editora Insular, 2013. 
EM

Como pensar a identidade nacional em zonas de Fronteira? Uma análise a partir de dois conjuntos de cidades-gêmeas brasileiro-argentinas. Revista Boletim Goiânio de Geografia (BGG), v. 39, n. 55900, p. 1-18, 2019. Disponível em: https://www.revistas.ufg.br/bgg/article/view/55900/33387

Acesso em: mai. 2020.

FERREIRA, Clarisse et. al. O SIS-Fronteira na perspectiva dos profissionais de saúde atuantes no município de Corumbá-MS. In: MORETTI, Cézar Eduardo, MARIANI, Milton. Estudos fronteiriços: desafios perspectivas e práticas. Campo Grande- MS. Editora UFSM 2015.

HAESBAERT, Rogério. Região e Redes Transfronteiriças em Áreas de Migração Brasileira nos Vizinhos do Mercosul. In: STROHAECKER, Tânia Marques (org.) et al. Fronteiras e Espaço Global. Porto Alegre: AGB-Seção Porto Alegre, 1998. p.59-68.

ITAIPÚ/MUNICIPALIDAD DE NUEVA ESPERANZA. Plan de ordenamiento territorial y ambiental y plan director de la ciudad de Nueva Esperanza. Nueva Esperanza, 2016.

MARTIN, André Roberto. Fronteiras e Nações. São Paulo: Contexto, 1997.

MACHADO, Lia Osório. Limites, Fronteiras, Redes. In:STROHAECKER, Tânia Marques (org.) et al.Fronteiras e Espaço Global. Porto Alegre: AGB-Seção Porto Alegre, 1998.

MACHADO, Lia Osório. Estado, territorialidades, redes. Cidades Gêmeas na fronteira sul americana. In: SILVEIRA, Maria Laura (Org.). Continente em chamas: globalização e território na América Latina. Rio de Janeiro: Civilização Brasileira, 2005. p. 244-280.

SANTOS, Gisleine. Redes e territórios: reflexões sobre a migração. In: DIAS, Leila Christina e SILVEIRA, Rogério L. Lima da. Redes, sociedades e territórios. Santa Cruz do Sul: Edunisc, 2005.

SANTOS, Milton. A Natureza do Espaço: técnica e tempo, razão e emoção. São Paulo, Hucitec, 1999. 